\title{
Prognostic value of interleukin-6 in atrial fibrillation: A cohort study and meta-analysis
}

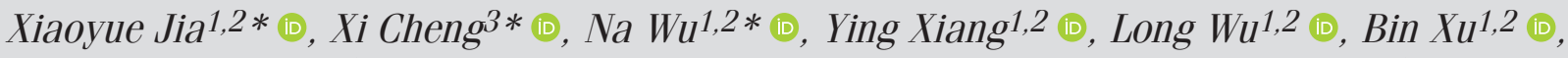

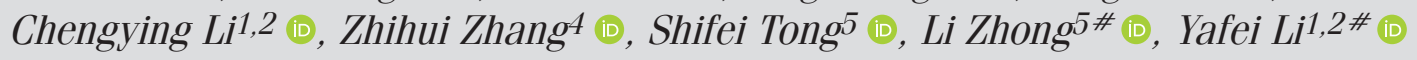

${ }^{1}$ Department of Epidemiology, College of Preventive Medicine, Army Medical University (Third Military Medical University); Chongqing-People's Republic of China

${ }^{2}$ Evidence-based Medicine and Clinical Epidemiology Center, Army Medical University (Third Military Medical University); Chongqing-People's Republic of China

${ }^{3}$ Department of Sciences\&Education, Chongqing General Hospital, University of Chinese Academy of Sciences; Chongqing-People's Republic of China

${ }^{4}$ Department of Cardiology, Southwest Hospital, Army Medical University (Third Military Medical University); Chongqing-People's Republic of China

${ }^{5}$ Cardiovascular Disease Center, Third Affiliated Hospital of Chongqing Medical University; Chongqing-People's Republic of China

\section{ABSTRACT}

Objective: The prognostic value of interleukin-6 (IL-6) in patients with atrial fibrillation (AF) has not been fully elucidated. Therefore, we conducted a cohort study and a meta-analysis to assess the predictive value of IL-6 for stroke and mortality in patients with AF.

Methods: A cohort study was performed in newly diagnosed non-valvular patients with AF. A total of 217 patients with AF were followed up for a mean of 27 months. A multivariate Cox regression analysis was used to evaluate the association between IL- 6 and stroke/all-cause mortality. The incremental value was also assessed by adding IL-6 to the CHA2DS2-VASc score. Besides, a meta-analysis of all reported cohort studies and our cohort study was conducted to validate the association of circulating IL-6 and stroke/mortality in patients with AF.

Results: Our cohort study showed that elevated plasma level of IL- 6 was an independent risk factor for predicting stroke [hazard ratio (HR)=3.81; $95 \%$ confidence interval ( $\mathrm{Cl}), 1.11-13.05 ; \mathrm{p}=0.033$ ] and all-cause mortality (HR=3.11; $95 \% \mathrm{Cl}, 1.25-7.72 ; \mathrm{p}=0.015$ ) in patients with AF. Adding IL-6 levels to CHA2DS2-VASc score showed limited improvement of the predictive power for stroke [area under curve (AUC) from 0.81 to $0.88, p=0.006$ ]. Metaanalysis confirmed that increased circulating level of IL-6 was significantly associated with increased risk of stroke (pooled $\mathrm{HR}=1.97 ; 95 \% \mathrm{Cl}$, $1.22-3.17 ; \mathrm{p}=0.006$ ) and all-cause mortality (pooled $\mathrm{HR}=2.73 ; 95 \% \mathrm{Cl}, 2.29-3.25 ; \mathrm{p}<0.001$ ).

Conclusion: Increased circulating level of IL-6 was significantly associated with greater risk of stroke and all-cause mortality in patients with AF. Adding IL-6 biomarker to the CHA2DS2-VASc score may help to determine the management of AF treatment.

Keywords: atrial fibrillation, prognosis, interleukin-6, meta-analysis, stroke, mortality

Cite this article as: Jia X, Cheng X, Wu N, Xiang Y, Wu L, Xu B, et al. Prognostic value of interleukin-6 in atrial fibrillation: A cohort study and meta-analysis. Anatol J Cardiol 2021; 25: 872-9.

\section{Introduction}

Atrial fibrillation (AF) is the most common arrhythmia in clinical practice (1). The prevalence of $A F$ is estimated to be $0.4 \%$ to $1.0 \%$ in the general population (2). AF increases the risk of stroke, heart failure, and overall mortality (3). In patients with $A F$, the annual incidence of ischemic stroke is about $5 \%, 2-7$ times of that in patients without AF (4), and a doubling in mortality rate (5). Therefore, it is crucial to prevent the occurrence of adverse cardiovascular events and improve the prognosis of patients with AF.

Thromboembolism is the main cause of death and disability in patients with $\mathrm{AF}$, and stroke is the most common type of

\footnotetext{
${ }^{*}$ X.J., X.C. and N.W. contributed equally to this work.
}

\# L.Z. and Y.L. jointly directed the project and share the corresponding authorship. 


\section{HIGHLIGHTS}

- The elevated plasma level of interleukin (IL) 6 was an independent risk factor for predicting stroke and allcause mortality in patients with atrial fibrillation (AF).

- Adding IL-6 biomarker to the CHA2DS2-VASc score may help determine the management of $A F$ treatment.

- $\quad \mathrm{IL}-6$ is a promising prognostic biomarker to help optimize the strategies for risk stratification in patients with AF.

manifestation (6). The mechanism of occurrence and development of $A F$ is considered to be multifactorial. Several risk stratifications scoring schemes have been developed to determine which patients with $\mathrm{AF}$ have higher stroke risk. The most widely used scoring scheme is the CHA2DS2-VASC score (7). However, there remains a need for improving the predictive ability of CHA2DS2-VASc score. Studies have found that adding biomarkers such as von Willebrand factor, D-dimer, N-terminal proBtype natriuretic peptide, and high-sensitivity troponin $\mathrm{T}$ to the CHADS2 score improved the predictive accuracy $(8,9)$.

Although there is some evidence indicating that inflammation may be associated with $\operatorname{AF}(10)$, it may underlie pathogenesis of arrhythmia and vascular events (11). IL-6 is a pleiotropic cytokine, which can induce a pro-thrombotic state by increasing the expression of Şbrinogen, tissue factor, factor VIII, and von Willebrand factor, as well as by activating endothelial cells and increasing platelet production, which may contribute to the adverse outcome of $\operatorname{AF}(12,13)$. Several studies have evaluated the associations between circulating level of IL-6 and stroke/ mortality in patients with $\operatorname{AF}(14,15)$, but the results lack consistency. Therefore, we conducted a prospective cohort study to determine the association of plasma level of IL- 6 with stroke and all-cause mortality in patients with AF. In addition, we performed a meta-analysis to further validate the prognostic value of IL-6 in AF.

\section{Methods}

\section{Cohort study \\ Patients}

We consecutively recruited newly diagnosed patients with AF aged at least 18 years and hospitalized in Southwest Hospital of the Army Medical University in Chongqing, China, from December 2013 to August 2015. The diagnosis of AF was made according to the 2012 European Guidelines for Atrial Fibrillation (16). Exclusion criteria included mitral rheumatic valve disease or a prosthetic valve, infections, malignant tumors, connective tissue diseases (such as rheumatoid arthritis), other acute or chronic inflammatory diseases (such as giant cell arteritis). We collected demographic, epidemiological, and medical information from medical records and structured interviews. The study was approved by the Ethics Committee of Southwest Hospital of the Army Medical University. Written informed consent was obtained from all the patients.

\section{Outcomes and follow up}

Primary outcomes included all-cause mortality and stroke. All the patients were actively followed up annually by phone interviews. Stroke was defined as the first neurologic deficit that lasted for at least 24 hours and sub-classified as ischemic (with or without hemorrhagic conversion), hemorrhagic, or uncertain after discharge. The diagnosis of stroke was confirmed by screening the medical records. Next-of-kin reports, electronic medical notes, and the national register of death were used to verify the annual vital status and the cause of death of the patients. Patients known to be alive were censored at the time of last contact.

\section{Measurement of IL-6}

A fasting blood sample $(5 \mathrm{~mL})$ was drawn from each patient before any treatment. The plasma was separated into aliquots of $500-\mu \mathrm{L}$ straws and frozen at $-80^{\circ} \mathrm{C}$ immediately after processing until use. The plasma level of IL-6 was measured using MILLIPLEX MAP Human Th17 Magnetic Bead Panel kits (Millipore, Billerica, MA., USA) based on the Luminex xMAP technology (Luminex Corporation, Austin, TX., USA). Plates were run on the Luminex MagPix machine (Luminex Corporation). Raw data were collected using the Luminex XPONENT 4.2 software and analyzed using MILLIPLEX Analyst 5.1 software (Millipore). Concentrations of IL-6 were calculated using a standard curve. Two duplicate samples were run for quality control (replicate $\mathrm{OC} 1$ samples, low level; replicate QC2 samples, high level). The coefficients of variation of all repeated quality control samples were less than $10 \%$.

\section{Statistical analysis}

Frequency counts and proportions were used to report categorical data. For the description of continuous variables, means and standard deviation were used for normally distributed data, and median and interquartile ranges $\left(25^{\text {th }}-75^{\text {th }}\right.$ percentile) were used for non-normally distributed data. The best cutoff value of IL-6 was determined by X-tile software, which is a free software available from Yale University School of Medicine that can determine a cutoff point for continuous data with a time-dependent outcome (17). Univariate and multivariate Cox proportional hazards regression models were used to evaluate the association of IL-6 with stroke and all-cause mortality in patients with AF. Baseline variables with $p<0.05$ in univariate Cox regression model were included as covariates in the multivariate Cox regression model. Hazard ratios (HR) and $95 \%$ confidence interval (CI) were estimated. Kaplan-Meier curves were used to depict the cumulative risk of stroke and all-cause mortality in patients with AF by different IL-6 levels, and the significance of their differences was assessed using log-rank tests. A CHA2DS2-VASc stroke risk score (including congestive heart failure; hypertension; age $\geq 75$ years; 
diabetes; stroke, transient ischemic attack, or thromboembolism; vascular disease; age 65-74 years, and sex) was assigned to each patient. However, these schemes have only a modest predictive value for predicting "high-risk" patients. C-statistics were estimated to compare the predictive power between modified models, using methods recommended by Pencina et al. (18). Besides, we used the time-dependent area under the receiver operating characteristic curve (AUC) to compare the predictive ability between modified models (adding IL6 to the CHA2DS2-VASc score) (19). A 2-sided $p$ value $<0.05$ was considered to be statistically significant. All these statistical analyses were conducted using the Statistical Package for the Social Sciences statistical software (version 20.0; IBM Corp., Armonk, NY, USA) and R 3.5.2 (R Foundation for Statistical Computing, Vienna, Austria).

\section{Search strategy and inclusion criteria of meta-analysis}

We searched PubMed, EMBASE, Springer Link, Web of Science, CNKI, and supplemented with Google scholar search engine for relevant studies published from database establishment to January 2020. We used the following keywords, "interleukin 6," "inflammatory markers," "biomarker," "prognosis," and "atrial fibrillation." In addition, relevant review articles were also cross-referenced. The included studies had to satisfy the following predefined criteria: (i) the study was a cohort study; (ii) the study enrolled patients with AF; (iii) stroke or mortality events were assessed as outcomes; (iv) the study investigated the association between IL- 6 and outcome events. If studies were duplicated, the one with the most complete data was chosen.

\section{Data extraction and quality assessment of meta-analysis}

Two investigators (Xiaoyue Jia and $\mathrm{Na} \mathrm{Wu}$ ) independently extracted the data using a standard data extraction form. We extracted general data (first author's name, year of publication), study characteristics (country and study design), types of $A F$, mean age of participants, mean follow-up time, adverse outcomes, and information related to effect size like $\mathrm{HR}, 95 \% \mathrm{Cl}$, and cutoff values. If both univariate analysis and multivariate analysis were available for the studies, the adjusted $\mathrm{HR}(95 \% \mathrm{CI})$ from the multivariate analysis with a maximum number of adjusted variables were extracted priority.

The quality of studies was independently assessed by two reviewers (Xiaoyue Jia and Xi Cheng). The assessment was done using the primary criteria for non-randomized studies described in the Newcastle-Ottawa scale. The total scores ranged from 0 to 9 for these studies (Supplementary Table 1). Any disagreement between the reviewers was discussed and resolved by consensus.

\section{Statistical analysis of meta-analysis}

Statistical heterogeneity across studies was assessed using the $I^{2}$ statistic, and heterogeneity was considered to be significant if $\mathrm{I}^{2}>50 \%$. A fixed-effects model was used to calculate pooled effect sizes when $\mathrm{I}^{2} \leq 50 \%$. Otherwise, a random-effects model was applied. Funnel plot with or without contour enhancement was applied to detect publication bias owing to small study effects. RevMan 5.3 software (version 5.3, Cochrane Collaboration, Oxford, United Kingdom) was used to perform the meta-analysis.

\section{Results}

\section{Cohort study}

A total of 232 patients with newly diagnosed non-valvular AF were enrolled in the cohort, and $217(54.38 \%$ men) patients with a mean age of 63.41 years were followed up. The median follow-up time was 27 months (IOR 23-30 months). During follow-up, all-cause mortality rate was $11.06 \%$ and the incidence rate of stroke was $6.91 \%$ (Table 1). The optimal IL-6 cut-off values was $55.20 \mathrm{pg} / \mathrm{mL}$.

Age and left atrial diameter (LAD) in patients with AF and stroke or death was significantly larger than that without stroke or survivor (both $p<0.05$ ) (Supplementary Table 2). According to the result of univariate Cox regression analysis, age, history of coronary heart disease, and heart failure were significantly associated with all-cause mortality. Age, history of stroke, and diabetes were significant risk factors of stroke (Supplementary Tables 3, 4). These significant variables were further adjusted in the multivariate Cox regression model. The results of multivariate cox regression analysis indicated that the increased plasma level of IL-6 was significantly associated with increased risk of all-cause mortality and stroke with adjusted $\mathrm{HR} 3.81(95 \% \mathrm{Cl}$ $1.11-13.05 ; \mathrm{p}=0.033)$ and $3.11(95 \% \mathrm{Cl} 1.25-7.72 ; \mathrm{p}=0.015)$, respectively (Table 2). The Kaplan-Meier curve showed that patients with elevated IL-6 had a higher risk of all-cause mortality $(p<0.05)$ and for stroke ( $>>0.05)$ (Fig. 1 and 2).

We further evaluated the predictive power of the model by adding IL-6 bio-markers to the CHA2DS2-VASc score. Adding high IL-6 to the CHA2DS2-VASC score had a better predictive power for stroke, AUC was improved from 0.81 to 0.88 significantly at 12 -month follow-up time $(p=0.006)$, whereas the improvement was

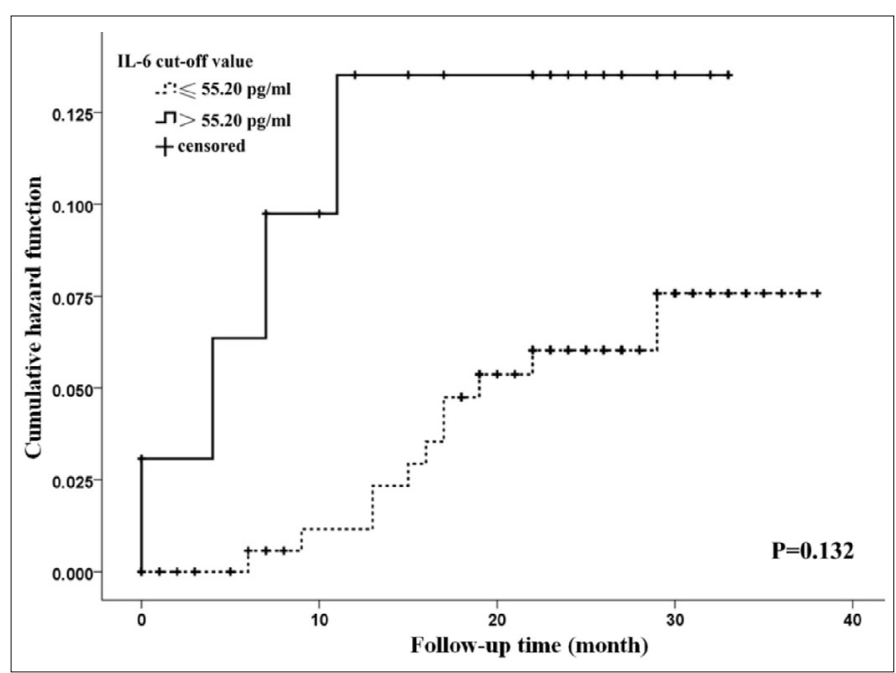

Figure 1. Cumulative risk of stroke in patients with atrial fibrillation at different plasma interleukin-6 levels 


\begin{tabular}{|c|c|}
\hline Patient characteristics & Number of patients (\%) \\
\hline Age, mean \pm SD, years & $63.41 \pm 12.20$ \\
\hline \multicolumn{2}{|l|}{ Sex } \\
\hline Male & $118(54.38)$ \\
\hline Female & $99(45.62)$ \\
\hline $\mathrm{BMI}$, mean $\pm \mathrm{SD}, \mathrm{kg} / \mathrm{m}^{2}$ & $24.32 \pm 3.59$ \\
\hline \multicolumn{2}{|l|}{ Education } \\
\hline Junior school and below & $173(79.72)$ \\
\hline High school and above & $44(20.27)$ \\
\hline \multicolumn{2}{|l|}{ Income (10,000 RMB/year) } \\
\hline$<2.5$ & $110(50.69)$ \\
\hline$\geq 2.5$ & $107(49.31)$ \\
\hline \multicolumn{2}{|l|}{ AF type } \\
\hline Paroxysmal & $68(31.34)$ \\
\hline Persistent & $149(68.66)$ \\
\hline \multicolumn{2}{|l|}{ Smoking status } \\
\hline Former/current & $73(33.64)$ \\
\hline Never & $144(66.36)$ \\
\hline \multicolumn{2}{|l|}{ Drinking status } \\
\hline Former/current & $76(35.02)$ \\
\hline Never & $141(64.98)$ \\
\hline \multicolumn{2}{|l|}{ Warfarin treatment } \\
\hline Yes & $65(29.96)$ \\
\hline No & $152(70.04)$ \\
\hline \multicolumn{2}{|l|}{ Statin treatment } \\
\hline Yes & $97(44.70)$ \\
\hline No & $120(55.30)$ \\
\hline \multicolumn{2}{|l|}{ History of combined diseases } \\
\hline Hypertension & $109(50.23)$ \\
\hline Diabetes & $33(15.21)$ \\
\hline Coronary heart disease & $83(38.25)$ \\
\hline Cardiomyopathy & $22(10.14)$ \\
\hline Heart failure & $78(35.94)$ \\
\hline TIA & $9(4.15)$ \\
\hline Vascular diseases & $14(6.45)$ \\
\hline Previous stroke & 18 (8.29) \\
\hline IL-6, median (range), pg/mL & $28.3(0.3-216.2)$ \\
\hline$\leq 55.2$ & 184 (84.79) \\
\hline$>55.2$ & $33(15.21)$ \\
\hline \multicolumn{2}{|l|}{ CHA2DS2-VASc score } \\
\hline$<2$ & 68 (32.72) \\
\hline$\geq 2$ & $146(67.28)$ \\
\hline $\begin{array}{l}\text { Follow-up time, mean (IOR), } \\
\text { month }\end{array}$ & $27(23-30)$ \\
\hline stroke & $15(6.91)$ \\
\hline All-cause mortality & $24(11.06)$ \\
\hline \multicolumn{2}{|c|}{$\begin{array}{l}\text { AF - atrial fibrillation; BMI - body mass index; IL - interleukin; SD - standard deviation } \\
\text { TIA - transient ischemic attack }\end{array}$} \\
\hline
\end{tabular}

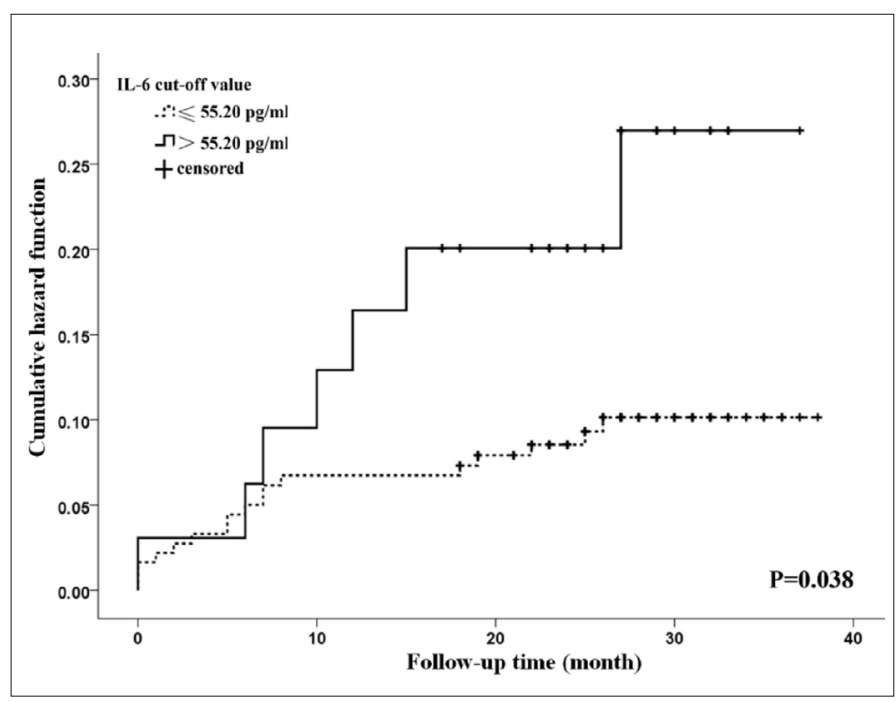

Figure 2. Cumulative risk of all-cause mortality in patients with atrial fibrillation at different plasma interleukin-6 levels

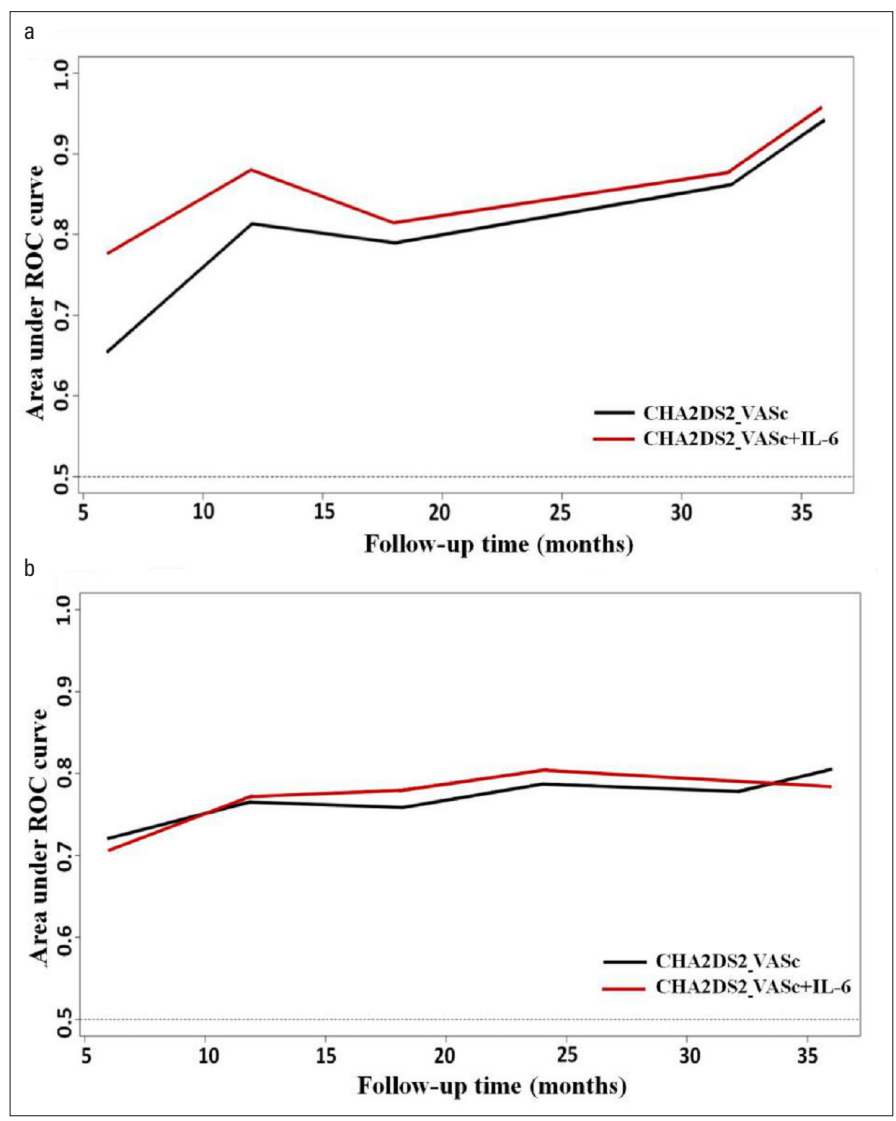

Figure 3. Area under the receiver operating curves (AUC) using a timedependent receiver operating curve analysis. (a) Time-dependent AUC of the two scores for stroke. (b) Time-dependent AUC of the two scores for all-cause mortality

non-statistically significant in all-cause mortality (AUC from 0.76 to $0.77, \mathrm{p}=0.635$ ) (Fig. 3). For stroke, the $\mathrm{c}$-statistic increased from 0.79 (95\% Cl, 0.69-0.88) to $0.83(95 \% \mathrm{Cl}, 0.74-0.93)$ when high IL-6 was added $(\mathrm{p}=0.213)$. As for the all-cause mortality, the discrimination index c-statistic was $0.75(95 \% \mathrm{Cl}, 0.68-0.82)$ in the prediction 


\begin{tabular}{|c|c|c|c|c|}
\hline \multirow[b]{2}{*}{ Variable } & \multicolumn{2}{|c|}{ Univariate Cox regression } & \multicolumn{2}{|c|}{ Multivariate Cox regression } \\
\hline & HR (95\% CI) & $P$-value & HR (95\% CI) & $P$-value \\
\hline \multicolumn{5}{|l|}{ Stroke } \\
\hline \multicolumn{5}{|c|}{ IL-6 (pg/mL) } \\
\hline$\leq 55.2$ & Reference & & Reference & \\
\hline \multicolumn{5}{|c|}{ All-cause mortality } \\
\hline \multicolumn{5}{|c|}{ IL-6 (pg/mL) } \\
\hline$\leq 55.2$ & Reference & & Reference & \\
\hline$>55.2$ & $2.46(1.02,5.93)$ & $0.045^{*}$ & $3.11(1.25,7.72)$ & $0.015^{*}$ \\
\hline
\end{tabular}

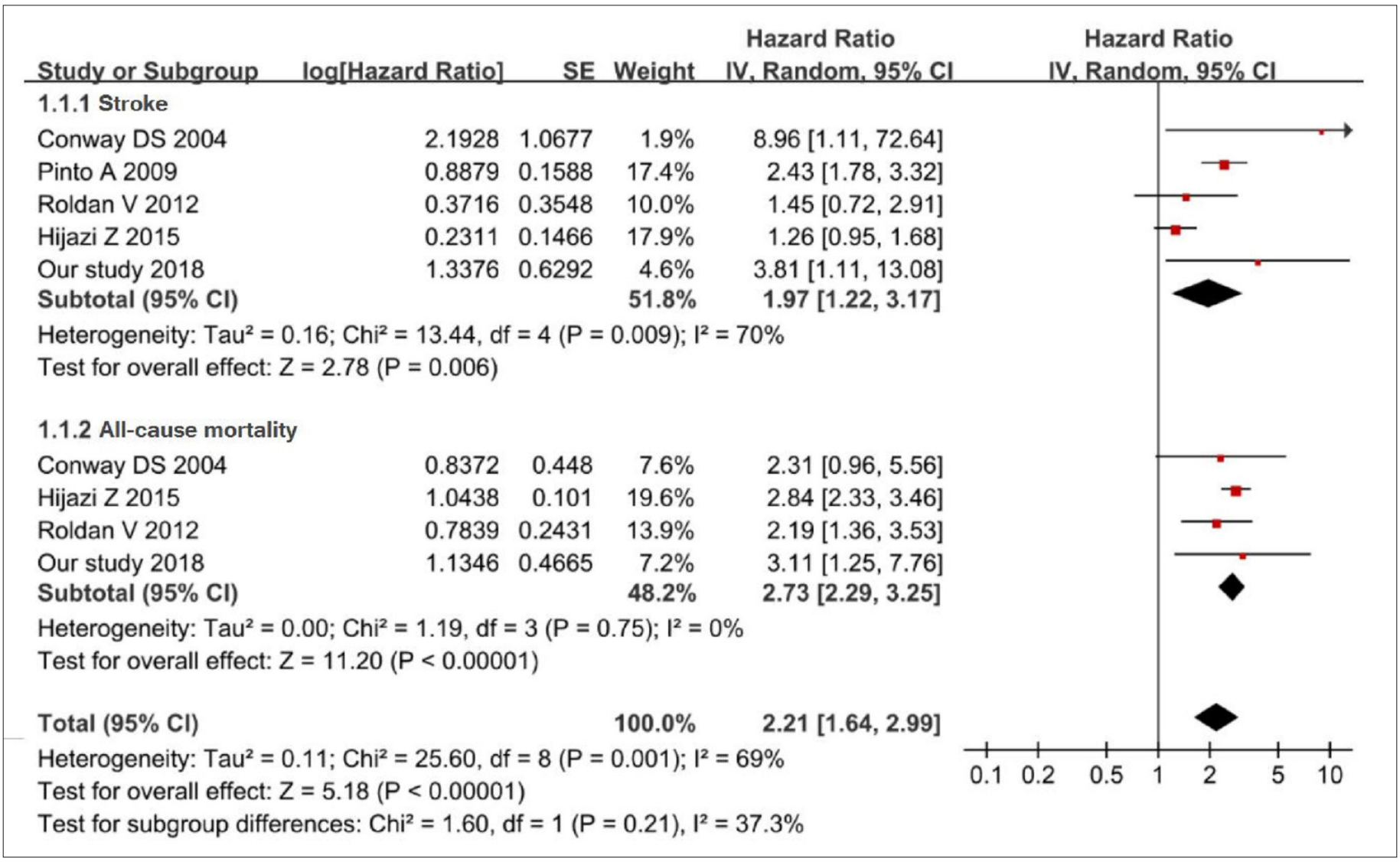

Figure 4. Forest plot of the relationship between the interleukin-6 level and outcomes. The squares and horizontal lines represent the hazards ratio (HR) and $95 \%$ confidence interval (CI), respectively. The area of the squares reflects the weight of each study. The diamond represents the pooled $\mathrm{HR}$ and $95 \% \mathrm{Cl}$

model consisting only of the CHA2DS2-VASc score. Adding high IL-6 to the score increased the c-statistic to $0.77(95 \% \mathrm{Cl}, 0.69-0.84)$, while it was not statistically significant $(\mathrm{p}=0.460)$.

\section{Meta-analysis}

A total of 299 studies were retrieved after initial search. After screening the titles and abstracts, 270 studies were excluded.
The remaining 29 studies were retrieved for the full text. Finally, 4 studies (20-23) met the inclusion criteria and a total of 16,334 participants were included in the final analysis (Supplementary Fig. 1). All the 4 included cohort studies investigated the predictive role of IL- 6 for stroke, and 3 studies $(20,21,23)$ with 15,961 patients investigated the predictive role of IL-6 for all-cause mortality. 
The mean age ranged from 63.0 to 76.0 years. The duration of follow-up for cohort studies ranged from 1.8 to 6.4 years, and all studies had a quality score of at least 5 . The detailed characteristics and NOS score are depicted in Supplementary Table 5. Metaanalysis of 4 published studies and our cohort study showed that higher level of IL-6 was significantly associated with an increased risk of stroke events. The pooled HR is $1.97(95 \% \mathrm{Cl}, 1.22-3.17$; $\mathrm{p}<0.05)$ with a medium heterogeneity $\left(\mathrm{I}^{2}=70 \%, \mathrm{p}=0.001\right)$ across the studies by random effects model (Fig. 4). A sensitivity analysis was performed, and the result showed that the study of Hijazi et al. (23) might be the source of heterogeneity. Compared with other studies, the study by Hijazi et al. (23) had shorter follow-up time (less than 2 two years), and there is one more inclusion criterion of patients with $\mathrm{AF}$ (at least one of the risk factors for stroke was required), which may lead to clinical heterogeneity. After excluding the study of Hijazi et al. (23), the pooled HR of stroke was 2.34 $(95 \% \mathrm{Cl}, 1.78-3.09 ; \mathrm{p}<0.05)$ with a low heterogeneity $\left(\mathrm{I}^{2}=26 \%\right.$, $\mathrm{p}=0.001$ ) (Supplementary Fig. 2).

Four studies (including our study) examined the association between IL-6 and all-cause mortality. The pooled HR of allcause mortality was $2.73(95 \% \mathrm{Cl}, 2.29-3.25 ; \mathrm{p}<0.001)$ with no significant heterogeneity $\left(\mathrm{I}^{2}=0 \%, \mathrm{p}=0.75\right)$ across the studies, indicating that elevated plasma level of IL- 6 was significantly associated with increased risk of all-cause mortality.

\section{Discussion}

We explored the association between IL-6 and the prognosis of patients with $\mathrm{AF}$ in a cohort study and meta-analysis. Our results showed that elevated IL-6 levels were significantly associated with higher risk of stroke and all-cause mortality in patients with AF. Adding plasma level of IL-6 could limit the improvement of the predictive power of CHA2DS2-VASc scores for stroke and all-cause mortality.

At present, the association of IL- 6 with AF prognosis remains controversial. Most studies show that the increase of IL- 6 is an independent risk factor for stroke or mortality in patients with $A F$ $(24,25)$. However, a few studies (23) reported that IL-6 level was not related to the risk of stroke in patients with AF. Our cohort study and meta-analysis consistently revealed that elevated IL-6 level was related to higher risk of stroke and death, independent of established clinical risk factors.

The pathophysiological mechanism involved in inflammation and the prognosis of AF remains undetermined. IL-6 is an established inflammatory biomarker, which is a circulating cytokine produced by monocytes, T lymphocytes, and epithelial cells (26). IL-6 also increases platelet production and platelet sensitivity to thrombin, stimulates transcription of fibrinogen, and is linked to endothelial cell activation and damage $(27,28)$. As a pleiotropic cytokine, IL-6 can induce CRP production by hepatocytes and is involved in immuno-inflammatory reaction by promoting neutrophil adhesion, atherosclerotic plaque rupture, and thrombus formation (29). It is therefore plausible that IL-6 inducing inflammation might mediate the prothrombic or hypercoagulable state that exists in $\mathrm{AF}(30)$, with consequences for left atrial thrombosis, stroke, and vascular events.

On the basis of clinical risk factors, the CHA2DS2-VASc score is the most commonly used stratification scheme to assess the risk of stroke in patients with AF and guide the use of anticoagulants, although its assessment ability and predictive accuracy is modest $(31,32)$. To increase prediction ability, incorporation of inflammatory biomarkers to CHA2DS2-VASc score become a hot research field $(33,34)$. Our cohort study indicated that modifying the CHA2DS2-VASc score by adding IL-6 could limit the improvement of the prediction ability for stroke and allcause mortality in patients with AF. Further epidemiological studies with large samples are needed to verify the clinical significance of our results.

\section{Study limitations}

Several limitations of this study should be considered in interpreting our results. Heterogeneity tests showed that there was significant heterogeneity for some studies investigating the predictive role of IL-6 for stroke, and no significant heterogeneity for studies examining the association between IL- 6 and allcause mortality. Because of the limited number of studies, our sensitivity analysis showed that the study of Hijazi et al. (23) might be the potential source of heterogeneity. Comparing the characteristics of the included studies, we found that mean age of participants, mean follow-up time, time points of the sample assay, and cut-off point varied among studies. In previous studies of meta-analysis, the cut-off values of IL-6 for predicting adverse outcomes were $3.35,20,0.89$, and $2.3 \mathrm{pg} / \mathrm{mL}$, respectively, (20-23) lower than our study. The cut-off value of IL6 in Hijazi et al. (23) and Roldan et al. (20) studies was the median of anticoagulant patients. The difference in assay methods might also partly contribute to the high heterogeneity among the studies. As a single-center study, our cohort study might have selection bias. Because of anticoagulant treatment rate in China is relatively low $(35,36)$, only $65(30.0 \%)$ patients received warfarin anti-coagulation in our cohort study, which may also introduce bias. Another limitation is the small sample size and insufficient follow-up time, which may have led to insufficient statistical power. Finally, although funnel plots showed no obvious publication bias (Supplementary Fig. 3) in our meta-analysis, the efficiency of publishing bias test is low because of the limited number of studies. Lau et al. (37) doubted that the widely used method of the funnel plot accurately predicts publication bias. A true standard measure of publication bias would require prospective registries of studies with detailed knowledge of which studies had been published and which were unpublished. Therefore, publication bias cannot be completely excluded.

\section{Conclusion}

In conclusion, our study suggested that high levels of IL-6 were significantly associated with stroke and death and other adverse outcomes in patients with AF. Moreover, compared to 
the classical CHADS-VASC score, adding IL-6 levels to CHADSVASC score showed limited improvement of the predictive power. IL-6 is a promising prognostic biomarker to help optimize the strategies for risk stratification, treatment, and prevention of adverse outcomes in patients with AF.

Institutional and financial support: This study was supported by the National Natural Science Foundation of China (No. 81502883 and 82073649 to N.W).

Conflict of interest: None declared.

Peer-review: Externally peer-reviewed.

Author contributions: Concept - L.Z., Y.L.; Design - X.J., X.C., N.W., L.Z., Y.L.; Supervision - X.J., X.C., N.W., L.Z., Y.L.; Fundings - N.W.; Materials - X.C., B.X.; Data collection \&/or processing -X.J., X.C., N.W., C.L., Z.Z., S.T.; Analysis \&/or interpretation - X.J., X.C., N.W., Y. X.; Literature search - Y. X., L.W.; Writing - X.J., X.C., N.W.; Critical review - L.Z., Y.L.

\section{References}

1. Nattel S. New ideas about atrial fibrillation 50 years on. Nature 2002; 415: 219-26. [Crossref]

2. Fuster V, Rydén LE, Cannom DS, Crijns HJ, Curtis $A B$, Ellenbogen $\mathrm{KA}$, et al. $2011 \mathrm{ACCF} / \mathrm{AHA} / \mathrm{HRS}$ focused updates incorporated into the ACC/AHA/ESC 2006 Guidelines for the management of patients with atrial fibrillation: a report of the American College of Cardiology Foundation/American Heart Association Task Force on Practice Guidelines developed in partnership with the European Society of Cardiology and in collaboration with the European Heart Rhythm Association and the Heart Rhythm Society. J Am Coll Cardiol 2011; 57: e101-98. [Crossref]

3. Krahn AD, Manfreda J, Tate RB, Mathewson FA, Cuddy TE. The natural history of atrial fibrillation: incidence, risk factors, and prognosis in the Manitoba Follow-Up Study. Am J Med 1995; 98: 476-84. [Crossref]

4. Bai Y, Bai R, Wu JH, Zhang T, Liu N, Shi XB, et al. Differences in Quality of Life Between Atrial Fibrillation Patients with Low Stroke Risk Treated With and Without Catheter Ablation. J Am Heart Assoc 2015; 4: e002130. [Crossref]

5. Wolf PA, Abbott RD, Kannel WB. Atrial fibrillation as an independent risk factor for stroke: the Framingham Study. Stroke 1991; 22: 983-8. [Crossref]

6. Benjamin EJ, Levy D, Vaziri SM, D'Agostino RB, Belanger AJ, Wolf PA. Independent risk factors for atrial fibrillation in a populationbased cohort. The Framingham Heart Study. JAMA 1994; 271: 8404. [Crossref]

7. Gage BF, Waterman AD, Shannon W, Boechler M, Rich MW, Radford MJ. Validation of clinical classification schemes for predicting stroke: results from the National Registry of Atrial Fibrillation. JAMA 2001; 285: 2864-70. [Crossref]

8. Sadanaga T, Kohsaka S, Ogawa S. D-dimer levels in combination with clinical risk factors can effectively predict subsequent thromboembolic events in patients with atrial fibrillation during oral anticoagulant therapy. Cardiology 2010; 117: 31-6. [Crossref]

9. Christersson C, Wallentin L, Andersson U, Alexander JH, Ansell J, De Caterina $\mathrm{R}$, et al. D-dimer and risk of thromboembolic and bleeding events in patients with atrial fibrillation--observations from the ARISTOTLE trial. J Thromb Haemost 2014; 12: 1401-12. [Crossref]

10. Camm AJ, Lip GY, De Caterina R, Savelieva I, Atar D, Hohnloser SH, et al. 2012 focused update of the ESC Guidelines for the management of atrial fibrillation: an update of the 2010 ESC Guidelines for the management of atrial fibrillation. Developed with the special contribution of the European Heart Rhythm Association. Eur Heart J 2012; 33: 2719-47.

11. Guo Y, Lip GY, Apostolakis S. Inflammation in atrial fibrillation. J Am Coll Cardiol 2012; 60: 2263-70. [Crossref]

12. Harada $M$, Van Wagoner DR, Nattel $S$. Role of inflammation in atrial fibrillation pathophysiology and management. Circ J 2015; 79: 495-502. [Crossref]

13. Frustaci A, Chimenti C, Bellocci F, Morgante E, Russo MA, Maseri A. Histological substrate of atrial biopsies in patients with lone atrial fibrillation. Circulation 1997; 96: 1180-4. [Crossref]

14. Grönefeld GC, Lilienthal J, Kuck KH, Hohnloser SH; Pharmacological Intervention in Atrial Fibrillation (PIAF) Study investigators. Impact of rate versus rhythm control on quality of life in patients with persistent atrial fibrillation. Results from a prospective randomized study. Eur Heart J 2003; 24: 1430-6.

15. The Stroke Risk in Atrial Fibrillation Working Group. Independent predictors of stroke in patients with atrial fibrillation. A systematic review. Neurology 2007; 69: 546-54. [Crossref]

16. Overbeck P; Europäische Gesellschaft für Kardiologie. Update 2012: Neue europäische Leitlinien bei Vorhofflimmern [Update 2012: new European guidelines for atrial fibrillation]. MMW Fortschr Med 2012; 154: 18-9. [Article in German] [Crossref]

17. Camp RL, Dolled-Filhart M, Rimm DL. X-tile: a new bio-informatics tool for biomarker assessment and outcome-based cut-point optimization. Clin Cancer Res 2004; 10: 7252-9. [Crossref]

18. Pencina MJ, D'Agostino RB Sr, D'Agostino RB Jr, Vasan RS. Evaluating the added predictive ability of a new marker: from area under the ROC curve to reclassification and beyond. Stat Med 2008; 27: 157-72. [Crossref]

19. Blanche P, Dartigues JF, Jacqmin-Gadda H. Estimating and comparing time-dependent areas under receiver operating characteristic curves for censored event times with competing risks. Stat Med 2013; 32: 5381-97. [Crossref]

20. Providência R. High sensitivity cardiac troponin T and interleukin-6 predict adverse cardiovascular events and mortality in anticoagulated patients with atrial fibrillation: a rebuttal. J Thromb Haemost 2012; 10: 2413; author reply 2014-5. [Crossref]

21. Conway DS, Buggins $P$, Hughes $E$, Lip GY. Prognostic significance of raised plasma levels of interleukin- 6 and $C$-reactive protein in atrial fibrillation. Am Heart J 2004; 148: 462-6. [Crossref]

22. Pinto A, Tuttolomondo A, Casuccio A, Di Raimondo D, Di Sciacca R, Arnao $\mathrm{V}$, et al. Immuno-inflammatory predictors of stroke at followup in patients with chronic non-valvular atrial fibrillation (NVAF). Clin Sci (Lond) 2009; 116: 781-9. [Crossref]

23. Hijazi Z, Aulin J, Andersson U, Alexander JH, Gersh B, Granger CB, et al.; ARISTOTLE Investigators. Biomarkers of inflammation and risk of cardiovascular events in anticoagulated patients with atrial fibrillation. Heart 2016; 102: 508-17. [Crossref]

24. Ridker PM, Buring JE, Shih J, Matias M, Hennekens CH. Prospective study of C-reactive protein and the risk of future cardiovascular events among apparently healthy women. Circulation 1998; 98: 731-3. [Crossref]

25. Ridker PM. Role of inflammatory biomarkers in prediction of coronary heart disease. Lancet 2001; 358: 946-8. [Crossref] 
26. Turagam MK, Mirza M, Werner PH, Sra J, Kress DC, Tajik AJ, et al. Circulating Biomarkers Predictive of Postoperative Atrial Fibrillation. Cardiol Rev 2016; 24: 76-87. [Crossref]

27. Burstein SA, Peng J, Friese P, Wolf RF, Harrison P, Downs T, et al. Cytokine-induced alteration of platelet and hemostatic function. Stem Cells 1996; 14 Suppl 1: 154-62. [Crossref]

28. Yudkin JS, Stehouwer CD, Emeis JJ, Coppack SW. C-reactive protein in healthy subjects: associations with obesity, insulin resistance, and endothelial dysfunction: a potential role for cytokines originating from adipose tissue? Arterioscler Thromb Vasc Biol 1999; 19: 972-8. [Crossref]

29. Paquissi FC. The Predictive Role of Inflammatory Biomarkers in Atrial Fibrillation as Seen through Neutrophil-Lymphocyte Ratio Mirror. J Biomark 2016; 2016: 8160393. [Crossref]

30. Chung MK, Martin DO, Sprecher D, Wazni O, Kanderian A, Carnes $C A$, et al. C-reactive protein elevation in patients with atrial arrhythmias: inflammatory mechanisms and persistence of atrial fibrillation. Circulation 2001; 104: 2886-91. [Crossref]

31. European Heart Rhythm Association; European Association for Cardio-Thoracic Surgery, Camm AJ, Kirchhof P, Lip GY, Schotten U, Savelieva I, Ernst S, et al. Guidelines for the management of atrial fibrillation: the Task Force for the Management of Atrial Fibrillation of the European Society of Cardiology (ESC). Eur Heart J 2010; 31: 2369-429. [Crossref]
32. Lip GY, Nieuwlaat R, Pisters R, Lane DA, Crijns HJ. Refining clinical risk stratification for predicting stroke and thromboembolism in atrial fibrillation using a novel risk factor-based approach: the euro heart survey on atrial fibrillation. Chest 2010; 137: 263-72. [Crossref]

33. Senoo K, Lau YC, Lip GY. Updated NICE guideline: management of atrial fibrillation (2014). Expert Rev Cardiovasc Ther 2014; 12: 1037-40. [Crossref]

34. Goette A, Kalman JM, Aguinaga L, Akar J, Cabrera JA, Chen SA, et al.; Document Reviewers: Osmar A. Centurion (Paraguay), KarlHeinz Kuck (Germany), Kristen K. Patton (USA), John L. Sapp (Canada), Martin Stiles (New Zealand), Jesper Hastrup Svendsen (Denmark), and Gaurav A. Upadhyay (USA); Review coordinator: Alena Shantsila (UK). EHRA/HRS/APHRS/SOLAECE expert consensus on Atrial cardiomyopathies: Definition, characterisation, and clinical implication. J Arrhythm 2016; 32: 247-78. [Crossref]

35. Chang SS, Dong JZ, Ma CS, Du X, Wu JH, Tang RB, et al. Current Status and Time Trends of Oral Anticoagulation Use Among Chinese Patients With Nonvalvular Atrial Fibrillation: The Chinese Atrial Fibrillation Registry Study. Stroke 2016; 47: 1803-10. [Crossref]

36. Chao TF, Chiang CE, Lin YJ, Chang SL, Lo LW, Hu YF, et al. Evolving Changes of the Use of Oral Anticoagulants and Outcomes in Patients With Newly Diagnosed Atrial Fibrillation in Taiwan. Circulation 2018; 138: 1485-7. [Crossref]

37. Lau J, loannidis JP, Terrin N, Schmid CH, Olkin I. The case of the misleading funnel plot. BMJ 2006; 333: 597-600. [Crossref] 


\begin{tabular}{|ll}
\hline Supplementary Table 1. Quality assessment score scale & Score \\
\hline Item &
\end{tabular}

NOS score scale for cohort studies*

\section{Selection}

(1) Representativeness of the exposed cohort

Truly representative of the average status in the community

Somewhat representative of the average status in the community

Selected group of users (e.g. nurses, volunteers)

No description of the derivation of the cohort

(2) Selection of the non-exposed cohort

Drawn from the same community as the exposed cohort

Drawn from a different source

No description of the derivation of the non-exposed cohort

3) Ascertainment of exposure

Secure record (e.g. surgical records)

Structured interview

Written self-report

No description

(4) Demonstration that outcome of interest was not present at the start of study

Yes

No

\section{Comparability}

Comparability of cohorts on the basis of the design or analysis

Study controls for the most important factor

Study controls for any additional factor

\section{Outcome}

(1) Assessment of outcome

Independent blind assessment

Record linkage

Self-report

No description

(2) Was follow-up long enough for outcomes to occur?

Yes

No

(3) Adequacy of follow up of cohorts

Complete follow-up - all subjects accounted for

Subjects lost to follow-up unlikely to introduce bias

Follow-up rate is low and no description of those lost

*A study can be awarded a maximum of one score for each numbered item within the Selection and Outcome categories. A maximum of two scores can be given for Comparability. 


\begin{tabular}{|c|c|c|c|c|c|c|}
\hline \multicolumn{7}{|c|}{ Supplementary Table 2. Baseline information of patients with AF with different outcomes } \\
\hline \multirow[b]{2}{*}{ Variable } & \multicolumn{3}{|c|}{ Death outcome } & \multicolumn{3}{|c|}{ Stroke outcome } \\
\hline & Death (24) & Survivor (193) & $P$-value & Stroke (15) & Without stroke (202) & $P$-value \\
\hline Sex & & & 0.982 & & & 0.993 \\
\hline Male & $13(54.17 \%)$ & $105(44.40 \%)$ & & $8(53.33 \%)$ & $110(54.46 \%)$ & \\
\hline BMI $\left(\mathrm{kg} / \mathrm{m}^{2}\right)$ & $25.06 \pm 4.29$ & $24.23 \pm 3.50$ & 0.289 & $23.18 \pm 3.24$ & $24.40 \pm 3.61$ & 0.205 \\
\hline Income (10,000 RMB/year) & 0.170 & & & 0.391 & & \\
\hline$<2.5$ & $9(37.50 \%)$ & $101(52.33 \%)$ & & $6(40.00 \%)$ & $104(51.49 \%)$ & \\
\hline$\geq 2.5$ & $15(62.50 \%)$ & $92(47.27 \%)$ & & $9(60.00 \%)$ & $98(48.51 \%)$ & \\
\hline Warfarin & $8(33.33 \%)$ & $57(29.53 \%)$ & 0.702 & $7(46.67 \%)$ & $58(28.71 \%)$ & 0.153 \\
\hline Statins & $14(58.33 \%)$ & $83(43.01 \%)$ & 0.154 & $8(53.33 \%)$ & $89(44.06 \%)$ & 0.486 \\
\hline \multicolumn{7}{|l|}{ Comorbidity } \\
\hline Hypertension & $16(66.67 \%)$ & $93(48.19 \%)$ & 0.088 & $10(66.67 \%)$ & $99(49.01 \%)$ & 0.187 \\
\hline Diabetes & $5(20.83 \%)$ & $28(14.51 \%)$ & 0.379 & $6(40.00 \%)$ & $27(13.37 \%)$ & 0.014 \\
\hline Coronary heart disease & $14(58.33 \%)$ & $69(35.75 \%)$ & 0.032 & $7(46.67 \%)$ & $76(37.62 \%)$ & 0.487 \\
\hline Cardiomyopathy & $4(16.67 \%)$ & $18(9.33 \%)$ & 0.278 & $0(0.00 \%)$ & $22(10.89 \%)$ & 0.374 \\
\hline Heart failure & $19(79.17 \%)$ & $59(30.57 \%)$ & $<0.001$ & $7(46.67 \%)$ & $71(35.15 \%)$ & 0.370 \\
\hline Left ventricular $\mathrm{EF}$ \% & $45.52 \pm 12.94$ & $56.65 \pm 12.81$ & $<0.001$ & $55.87 \pm 13.26$ & $55.37 \pm 13.30$ & 0.888 \\
\hline
\end{tabular}




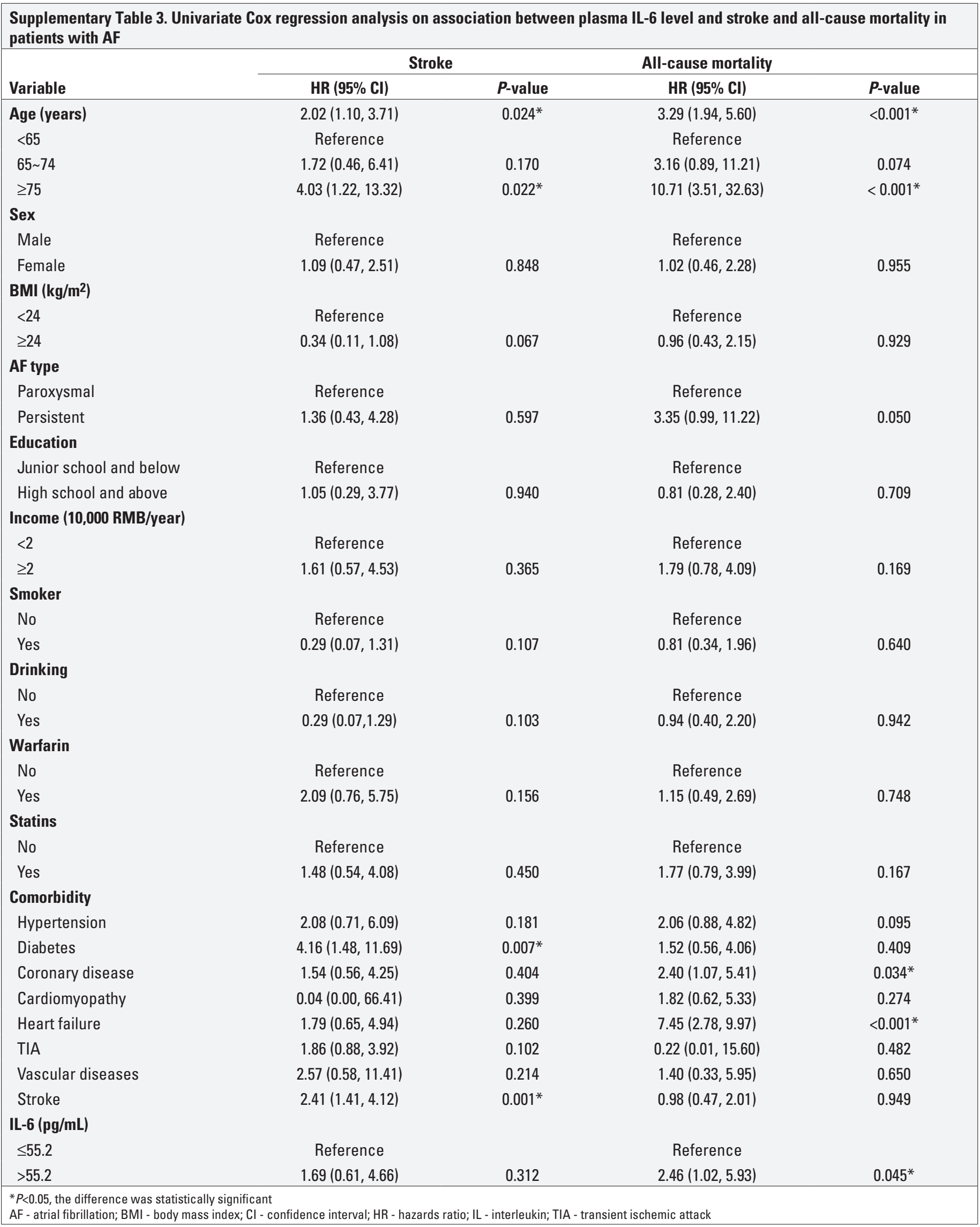




\begin{tabular}{|c|c|c|c|c|}
\hline \multicolumn{5}{|c|}{$\begin{array}{l}\text { Supplementary Table 4. Multivariate Cox regression analysis on association between plasma IL-6 level and stroke and all-cause mortality in } \\
\text { patients with AF }\end{array}$} \\
\hline Variable & \multicolumn{2}{|c|}{ Stroke } & \multicolumn{2}{|c|}{ All-cause mortality } \\
\hline Age (years) & $2.06(1.08,3.90)$ & $0.027^{*}$ & $3.10(1.70,5.67)$ & $0.001^{*}$ \\
\hline$<65$ & Reference & & Reference & \\
\hline$\geq 75$ & $4.22(1.23,14.54)$ & $0.022^{*}$ & $8.91(2.64,30.03)$ & $0.001^{*}$ \\
\hline \multicolumn{5}{|l|}{ Comorbidity } \\
\hline Diabetes & $3.34(1.13,9.82)$ & $0.029^{*}$ & - & - \\
\hline Coronary disease & - & - & $1.10(0.45,2.64)$ & 0.833 \\
\hline Heart failure & - & - & $5.41(1.99,14.65)$ & $0.001 *$ \\
\hline$\leq 55.2$ & Reference & & Reference & \\
\hline$>55.2$ & $3.81(1.11,13.05)$ & $0.033^{*}$ & $3.11(1.25,7.72)$ & $0.015^{*}$ \\
\hline $\begin{array}{l}{ }^{*} P<0.05 \text {, the difference } w \\
\text { Cox proportional hazards } \\
\text { disease and history of he } \\
\text { AF - atrial fibrillation; } \mathrm{Cl} \text { - }\end{array}$ & $\begin{array}{l}\text { unavailable. } \\
\text { or age, types of } A F \text {, hist } \\
\text { I selection strategy. } \\
\text { zard ratio; IL - interleu }\end{array}$ & istory of $s$ & ortality, adjusted for a & story of co \\
\hline
\end{tabular}

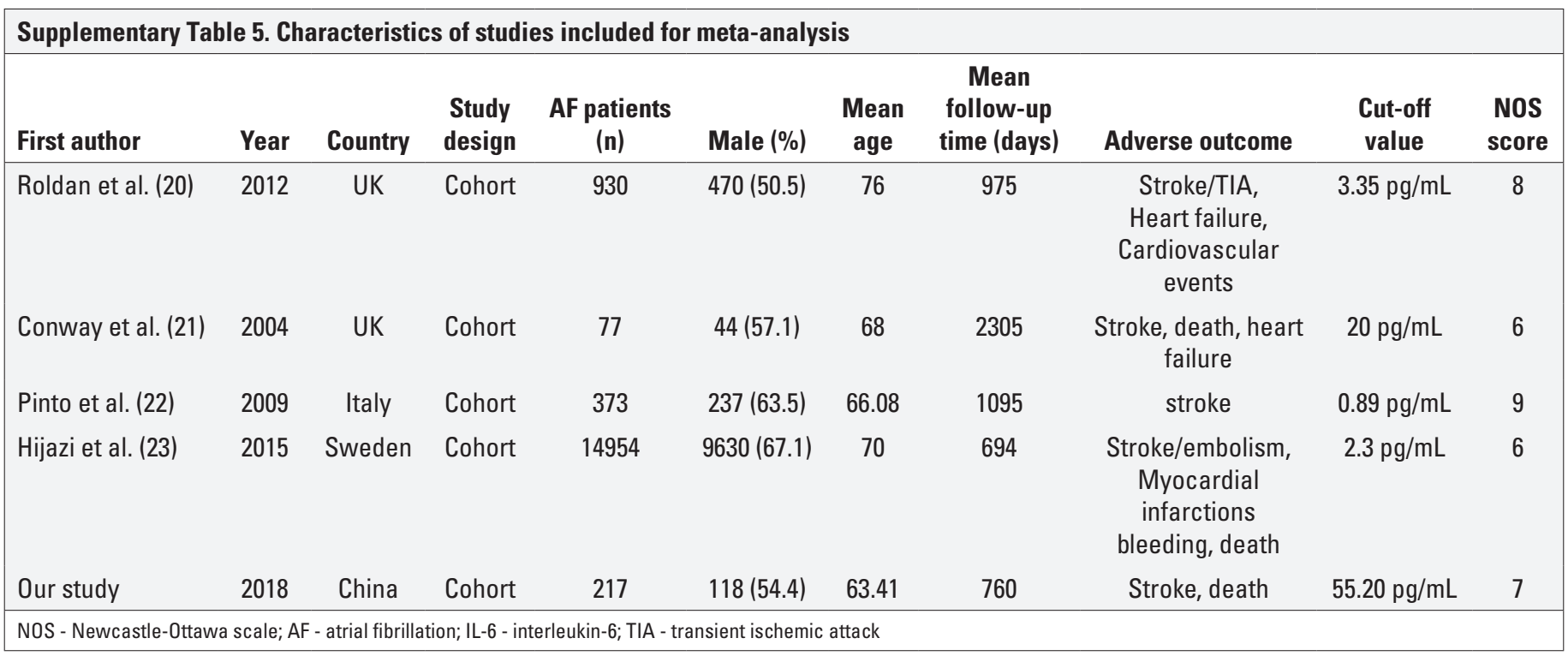




\section{9 studies identified}

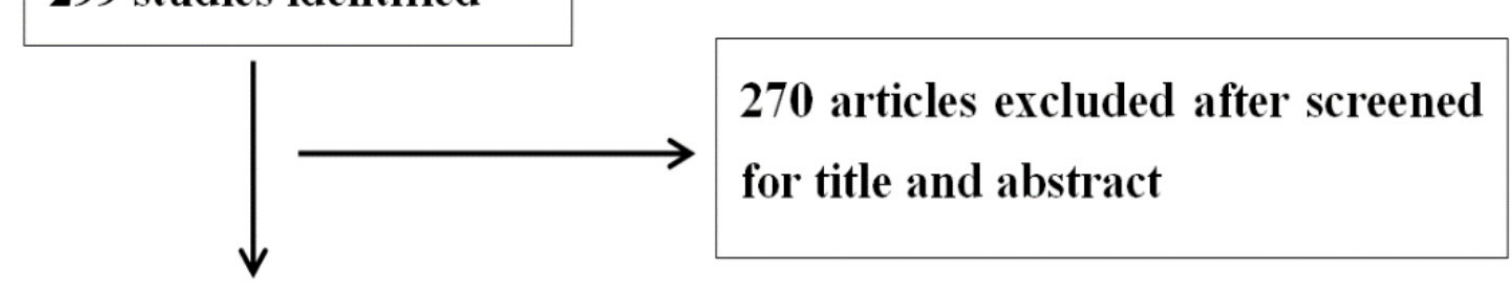

\section{9 articles identified and} screened for full text

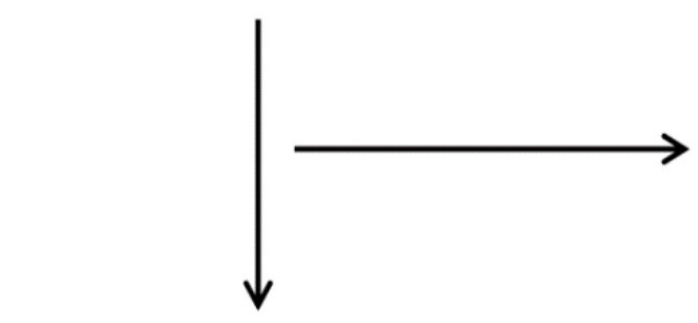

\section{5 articles excluded}

Reviews (n=4)

Case-control studies $(n=2)$

Animal studies (n=5)

Duplicates $(\mathbf{n}=2)$

Not relevant $(n=12)$

\section{4 articles included}

Supplementary Figure 1. Flowcharts presenting the pipeline of the search and data extraction

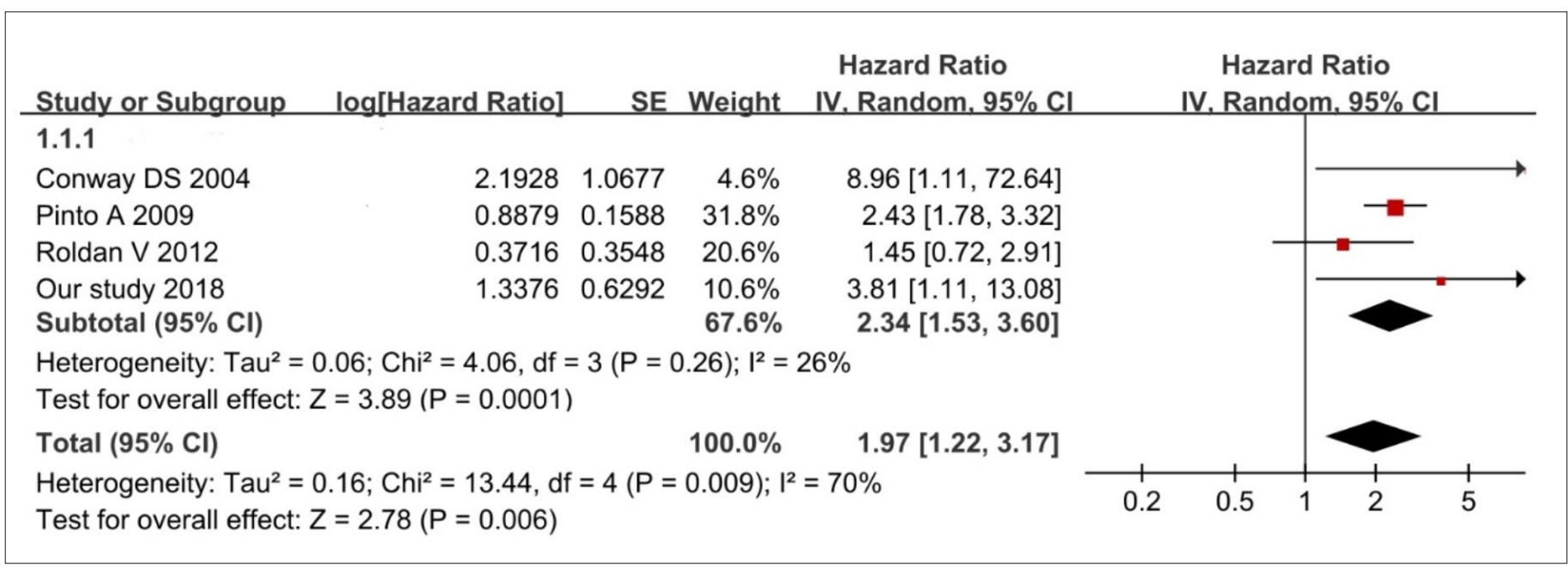

Supplementary Figure 2. Sensitivity analysis on association between plasma interleukin-6 level and stroke events 


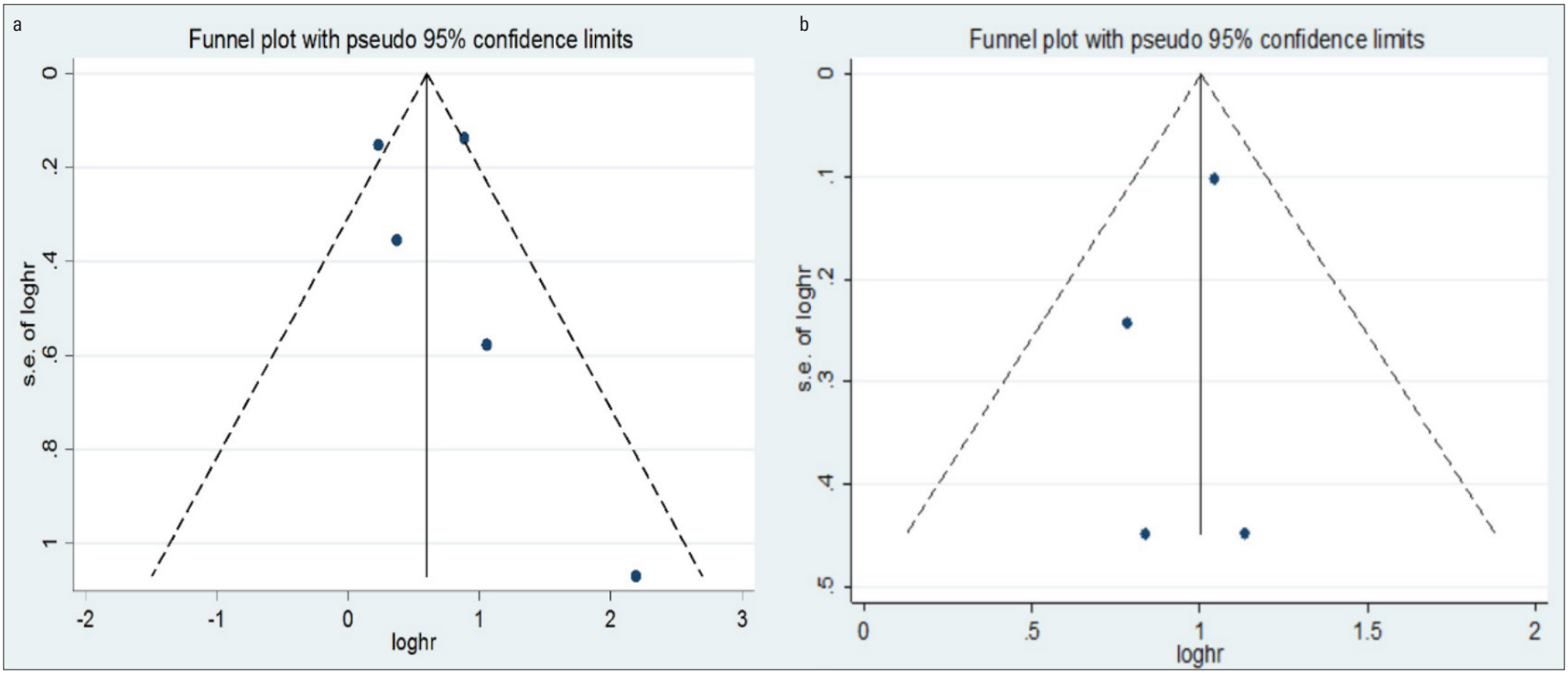

Supplementary Figure 3. Funnel plot for publication bias analysis. a) Stroke events and b) all-cause mortality events 